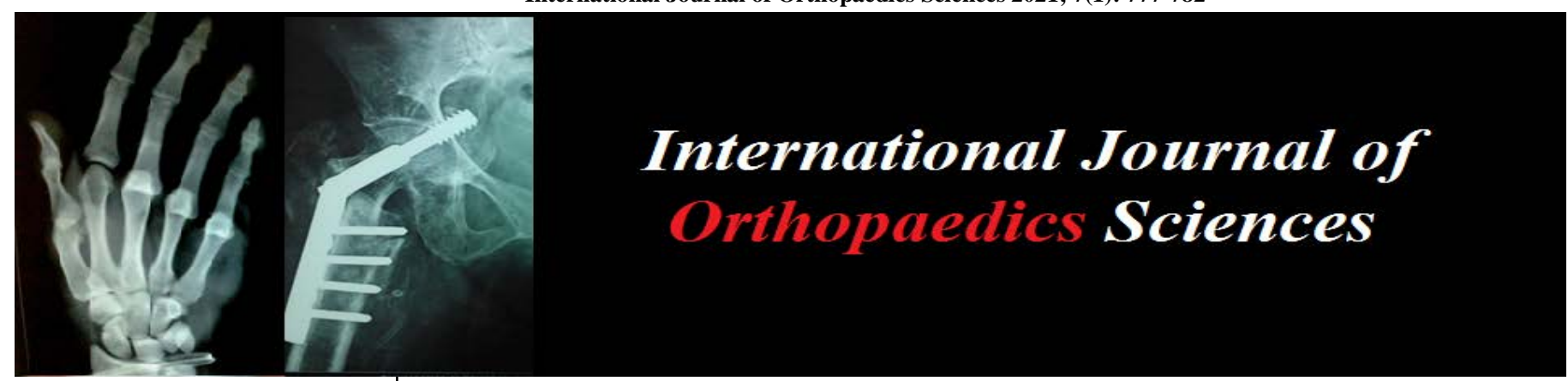

E-ISSN: 2395-1958

P-ISSN: 2706-6630

IJOS 2021; 7(1): 777-782

(C) 2021 IJOS

www.orthopaper.com

Received: 11-09-2020

Accepted: 15-12-2020

Dr. TH Prakashappa,

D'Ortho, MS Orthopaedics,

Professor and Head, Department

of Orthopaedics, SGITO,

Bengaluru, Karnataka, India

Dr. Yogananda Gali Hanumaih Junior Resident, SGITO,

Bengaluru, Karnataka, India

Dr. Shamsundar Y

Junior Resident, SGITO,

Bengaluru, Karnataka, India

Dr. Appasab Jaipal Murugunde

Junior Resident, SGITO,

Bengaluru, Karnataka, India
Corresponding Author:

Dr. Yogananda Gali Hanumaih

Junior Resident, SGITO,

Bengaluru, Karnataka, India

\section{Functional outcome of uncemented total hip arthroplasty in degenerative arthritis of hip}

\author{
Dr. TH Prakashappa, Dr. Yogananda Gali Hanumaih, Dr. Shamsundar Y \\ and Dr. Appasab Jaipal Murugunde
}

DOI: https://doi.org/10.22271/ortho.2021.v7.i11.2570

\section{Abstract}

Background: Total hip replacement is the most commonly performed adult reconstructive procedure. The most common condition for which total hip arthroplasty is done is severe osteoarthritis of the hip, accounting for $70 \%$ of cases. This procedure is indicated primarily in patients with severe pain and limitation in activities of daily living. To warrant doing Total hip replacement, pain must be refractory to conservative measures such as oral nonsteroidal anti-inflammatory medication, weight reduction, activity restriction, and the use of supports such as cane.

Objectives: To assess the functional outcome of uncemented total hip arthroplasty in patients with degenerative arthritis of hip, in terms of Pain relief, functional capacity, range of motion, absence of deformity, radiological assessment and comparing pre- operative and post-operative functional status with modified harris hip scoring system and to record any complications peri-operatively and in early post-operative period.

Methods: This is a prospective study conducted on 34 hips of 30 degenerative arthritis patients who underwent uncemented total hip replacement performed in the Department of Orthopaedics, Sanjay Gandhi Institute of Trauma and Orthopaedics, Bengaluru during November 2018 to March 2020. The patients were followed up at 6,12 and 24 weeks postoperatively and the functional outcome was evaluated using modified harris hip score.

Results: 34 hips of 30 patients, with degenerative arthritis were operated with uncemented THR. Patients were evaluated functionally and radiologically. Functional evaluation with modified harris hip score showed excellent results in 27 patients and good result in 3 patients. Radiological evaluation at the last follow up showed no signs of loosening or implant failure.

Conclusion: We have evaluated Total hip arthroplasty, using uncemented prosthesis in a short duration follow up. Our study suggests that the current generation of uncemented prosthesis used in the total hip replacement for degenerative arthritis of hip, provides satisfactory clinical and radiological outcomes after a short duration of follow up. Even though the study was not free of complications, the overall functional and radiological outcome showed excellent results.

Keywords: Osteoarthritis; Uncemented total hip replacement; Modified harris hip score

\section{Introduction}

Total hip replacement arthroplasty is a surgical procedure, which has relieved the incapacitating pain arising from the hip joint in millions of people. At present it is the most commonly performed adult reconstructive procedure ${ }^{[1]}$. Total hip arthroplasty is a remarkable surgical procedure especially in young patients that provides mobility, stability as well as better quality of life for thousands of patients throughout the world. Total hip arthroplasty can be either cemented or uncemented.

The incidence of chronic disabling conditions of the hip such as osteoarthritis, inflammatory arthritis and osteonecrosis is increasing. The most common condition for which total hip arthroplasty done is severe osteoarthritis of the hip, accounting for $70 \%$ of cases ${ }^{[2]}$. Causes for secondary osteoarthritis include post traumatic, developmental and connective tissue disorders. The primary indication for doing THR is the severe pain and limitation of activity of daily living that are caused by these conditions and the pain is refractory to conservative measures. Osteoarthritis is considered the most common disease of the locomotor system and is prevalent among middle aged and elderly adults ${ }^{[3]}$. Orthopaedic surgery has a critical role in the 
management of osteoarthritis ${ }^{[4-6]}$ as hip is the second most commonly affected large joint by osteoarthritis and no therapies exist currently to halt its progression. THR provides pain reduction and improves physical function and quality of life in most patients with end stage hip osteoarthritis ${ }^{[7]}$.

The field of total hip joint replacement is in an evolutionary state. The first total hip replacement was done in London by Phillip Wiles in $1938^{[8]}$. The procedure was further developed in the 1950s by pioneers such as McKee and Farrar ${ }^{[9]}$. This early work laid the groundwork for the innovative studies in the late 1960s by Sir John Charnley who, approached the problem of artificial hip joint design using the biomechanical principles of human hip joint function.

Cemented THA dramatically improves a patient's function and quality of life. With current prostheses and modern cementing techniques, the rate of femoral loosening appears to be substantially reduced. Regardless of the cementing technique, mechanical loosening occurs commonly in young, heavy, active patients and with certain prosthetic designs.

Noncemented total hip arthroplasty is a cost-effective procedure ${ }^{[10]}$ and was developed in response to evidence that poly and cement debris plays an important role in promoting bone lysis and loosening in cemented arthroplasty. Prosthetic devices have been developed that achieve fixation either by "press-fit" or by biologic ingrowth, without use of cement. Stabilization is achieved by interference fit of the implant into the femur in press-fit technique. With biologic ingrowth, fixation occurs by ingrowth of bone into a porous surface. Noncemented arthroplasty is frequently used in young patients with high physical demands, where a revision surgical procedure in the future is more likely. Preliminary data suggest that noncemented total hip arthroplasties have relatively low revision rate and excellent prosthetic durability. Evaluation of long-term outcomes of a procedure like total hip replacement is important to determine its durability. It provides a means of comparison of the results of different clinical interventions which may lead to changes in operative technique and implant design over time. The harris hip score is the most widely used scoring system for evaluating hip arthroplasty.

\section{Materials and Methods}

This is a prospective study conducted in the Department of Orthopaedics, Sanjay Gandhi Institute of Trauma and Orthopaedics, Bangalore during 18months period from November 2018 to March 2020. It is a hospital-based study with sample size of 30 .

\section{Inclusion criteria}

All cases undergoing primary total hip replacement in our institute which included,

1. Patients with age group $>18 y$ rs of either sex and $<70 y$ rs.

2. Patient with osteoarthritis hip (primary and secondary) which affects their activities of daily living.

3. X Ray of the patient's hip must show well established arthritic changes.

4. Patient with AVN grade 3 and above with radiological changes of arthritis.

5. Patients willing for total hip replacement surgery and giving informed written consent.

\section{Exclusion criteria}

1. Patients with failed total hip arthroplasty.

2. Patients with septic arthritis.
3. Patients with neuropathic joints, neurological defects around hip (paralyzed abductors).

4. Presence of active foci of infection in the body.

5. Patients who are unfit for surgery due to associated medical problems and Patients not willing for surgery.

A total of 30 patients, who had given an informed and written consent, posted for hip replacement surgery were included in to the study. All patients were operated upon for Total Hip Arthroplasty using uncemented acetabular cup and uncemented femoral stem by posterior southern moore approach.

\section{Post-operative management}

- Limb is kept in abduction with pillow between two lower limbs.

- Intravenous antibiotics are given for 5 days. Oral antibiotics started from 6th postoperative day and continued for another 4 days.

- On 1 post-operative day-

- check X rays are taken, drain is removed and dressing changed.

- Static quadriceps exercises, knee and ankle mobilisation done.

- Patient is made to sit. Gait training started using walker with tolerable weight bearing

- DVT prophylaxis - inj enoxheparin 40mg se OD for 3 days and oral anticoagulants (ecospirin 75mg OD) continued for 1 month.

- $\quad$ Suture removal done on 10 " post op day and patient was discharged from hospital.

\section{Advice at discharge}

- Not to squat.

- Not to sit cross legged.

- Not to use Indian toilets.

- Not to cross the lower limb across the midline

\section{Follow up}

The patients are reviewed with post op x-rays after surgery and at the end of $6,12,24$ weeks after the surgery and the outcome was assessed using modified harris hip score.

\section{Results}

\section{Age distribution}

Study subjects belonged to an age range of 21 years to 68 years with Median \pm IQR of $41.5 \pm 17$ years. Among the 30 study subjects, majority belonged to age group of 40-49 years.

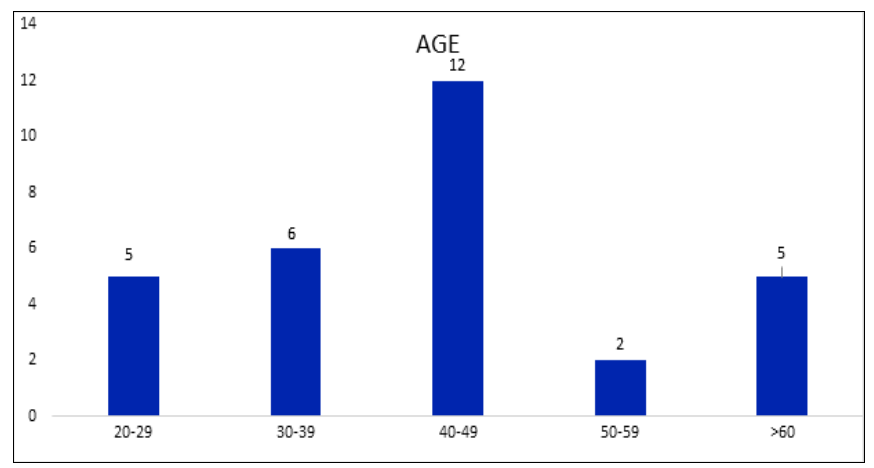

Fig 1: Graph showing age distribution 
Table 1: Showing age distribution

\begin{tabular}{|c|c|c|}
\hline Age & Frequency & Percent \\
\hline $20-29$ & 5 & 16.7 \\
\hline $30-39$ & 6 & 20.0 \\
\hline $40-49$ & 12 & 40.0 \\
\hline $50-59$ & 2 & 6.7 \\
\hline$>60$ & 5 & 16.7 \\
\hline Total & 30 & 100.0 \\
\hline Median + IQR & $41.50+17$ & \\
\hline
\end{tabular}

IQR: inter quartile range

\section{Gender Distribution}

In this study, 16 (53.3\%) were females and 14 (46.7\%) were males.

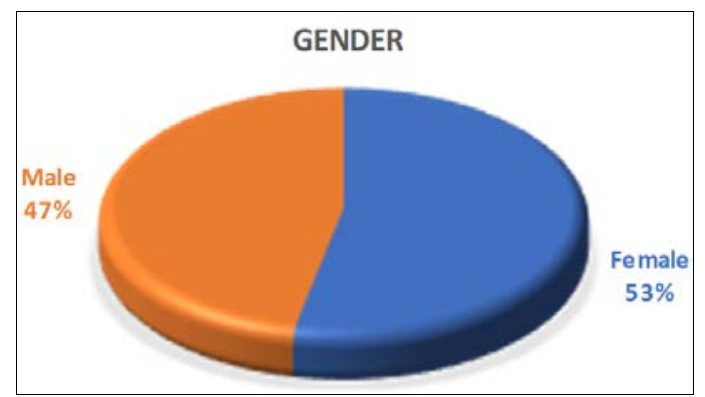

Fig 2: Pie chart showing Gender distribution

Table 2: Showing Gender distribution

\begin{tabular}{|c|c|c|}
\hline Gender & Frequency & Percent \\
\hline Female & 16 & 53.3 \\
\hline Male & 14 & 46.7 \\
\hline Total & 30 & 100.0 \\
\hline
\end{tabular}

\section{Side affected}

- Among 30 patients, 4 bilateral (13.3\%), 12 on left side (40\%) and 14 on right side (46.7\%) were affected.

- 26 patients underwent unilateral THR.

- 4 patients who were affected bilaterally, underwent staged bilateral THR at an interval of 6-12 weeks.

Table 3: Showing side affected

\begin{tabular}{|c|c|c|c|}
\hline \multicolumn{2}{|c|}{ Side } & Frequency & Percent \\
\hline \multicolumn{2}{|c|}{ Bilateral } & 4 & 13.3 \\
\hline \multirow{2}{*}{ Unilateral } & Left & 12 & 40.0 \\
\cline { 2 - 4 } & Right & 14 & 46.7 \\
\hline \multicolumn{2}{|c|}{ Total } & 30 & 100.0 \\
\hline
\end{tabular}

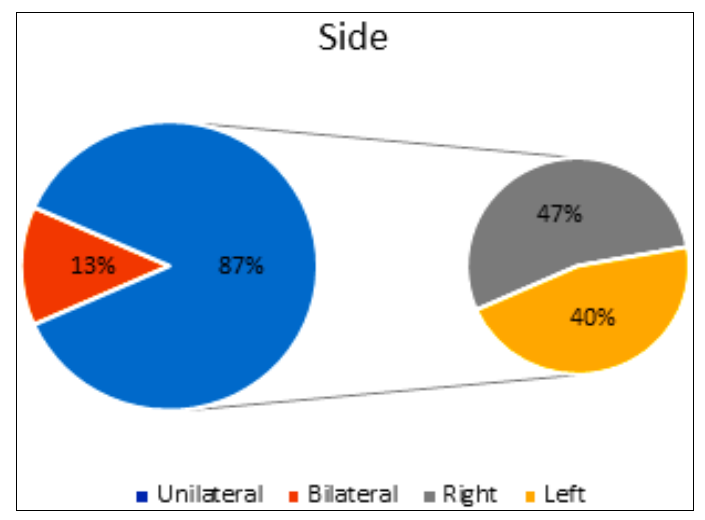

Fig 3: Pie chart showing side affected

\section{Indication}

The main indication for surgery was secondary OA in 30 hips
(88\%) in which most commonly it was due to AVN (22 hips, $64.70 \%$ ) followed by trauma (3 hips, 8.82\%) rheumatoid arthritis (2 hips, 5.88\%) Ankylosing spondylitis (2 hips, $5.88 \%$ ) and DDH (1 hip,2.94\%). In the remaining 4 hips, it was due to primary OA (12\%).

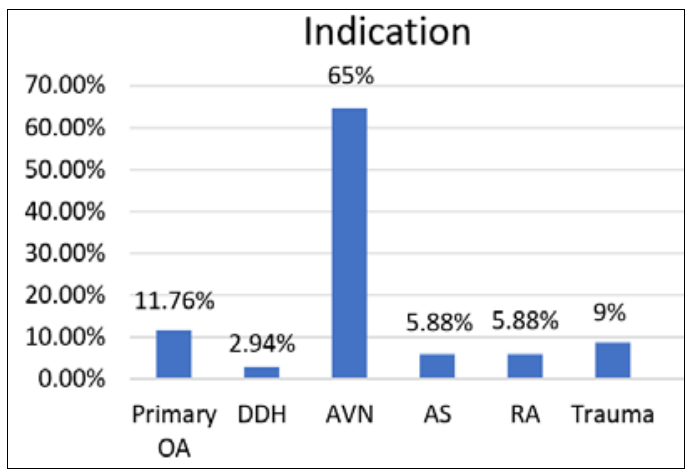

Fig 4: Graph showing Indications for surgery

Table 4: Indication for surgery

\begin{tabular}{|c|c|c|c|}
\hline \multicolumn{2}{|c|}{ Diagnosis } & Frequency & Percent \\
\hline \multicolumn{2}{|c|}{ Primary OA } & 4 & $11.76 \%$ \\
\hline \multirow{3}{*}{ Secondary OA } & DDH & 1 & $2.94 \%$ \\
\cline { 2 - 4 } & AVN & 22 & $64.70 \%$ \\
\cline { 2 - 4 } & AS & 2 & $5.88 \%$ \\
\cline { 2 - 4 } & RA & 2 & $5.88 \%$ \\
\cline { 2 - 4 } & Trauma & 3 & $8.82 \%$ \\
\hline \multicolumn{2}{|c|}{ Total } & 34 & 100.0 \\
\hline
\end{tabular}

\section{Outcome}

\section{Clinical results}

Mean preoperative Harris hip score was 42.5, ranging from 33 to 56. This score improved to 92.8 (86-97) at last follow up.

Table 5: Modified Harris hip score results

\begin{tabular}{|c|c|c|c|c|}
\hline Mean \pm SD & Pre-Op HHS & Post Op HHS & T value & P value \\
\hline Pain & $12.33 \pm 4.30$ & $42.20 \pm 1.99$ & 44.07 & $<0.05$ \\
\hline Function & $26.37 \pm 2.48$ & $41.77 \pm 1.47$ & 34.71 & $<0.05$ \\
\hline Absence of deformity & $0.80 \pm 1.62$ & 4.00 & 10.77 & $<0.05$ \\
\hline ROM score & $3.00 \pm 0.45$ & $4.83 \pm 0.37$ & 26.49 & $<0.05$ \\
\hline Total score & $42.50 \pm 7.08$ & $92.80 \pm 3.21$ & 48.43 & $<0.05$ \\
\hline
\end{tabular}

\section{Outcome analysis}

Pre operatively all patients (30) had poor scores (mean 42.5). The results showed a significant improvement (mean 92.8) postoperatively, where in 27 patients had an excellent score, 3 had good score. The outcome after total hip replacement was excellent in $90 \%$ and good in $10 \%$ of the study group.

(Excellent - 90 to 100 points, Good - 80 to 89 points, Fair - 70 to 79 points, Poor - below 70)

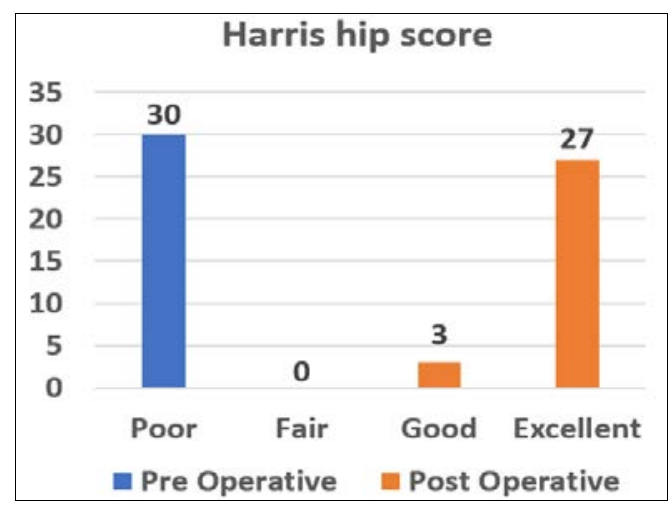




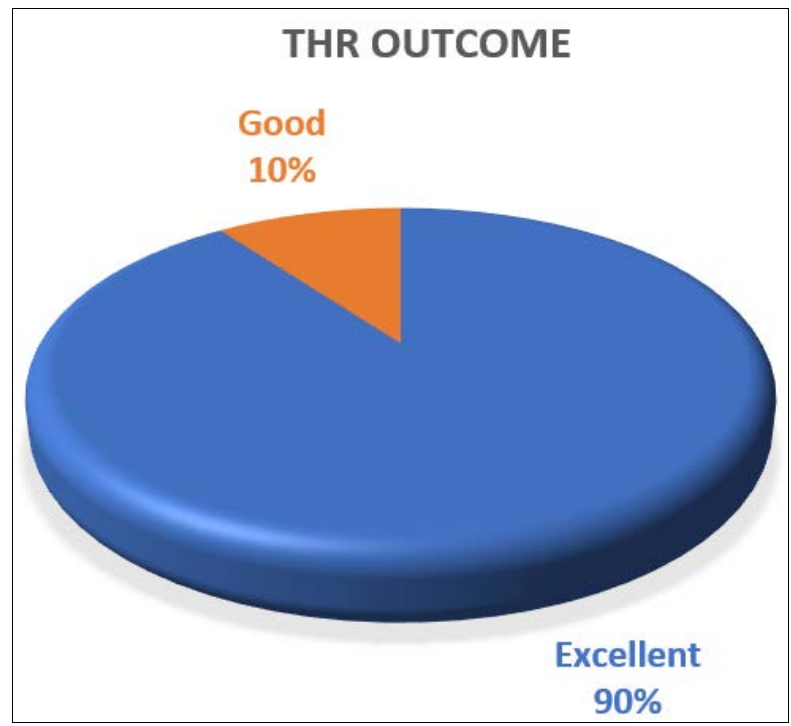

Fig 5: Clustered bar graph-preoperative and postoperative Harris hip score and HR outcome

\section{Radiographic results}

Results of the radiographic evaluation on all hips were as follows;

Table 6: Post-operative Acetabular cup angle

\begin{tabular}{|c|c|c|}
\hline Acetabular cup angle & Frequency & Percent \\
\hline$<40$ degree & 7 & 20.58 \\
\hline 40-45 degree & 14 & 41.17 \\
\hline 46-50 degree & 11 & 32.35 \\
\hline$>50$ degree & 2 & 5.88 \\
\hline Total & 34 & 100 \\
\hline
\end{tabular}

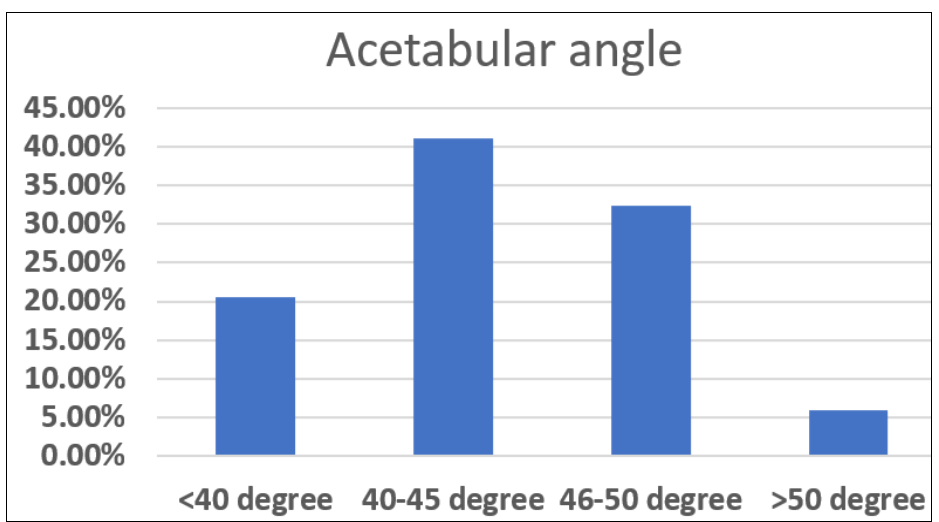

Fig 6: Acetabular cup angle

At the last follow up none of the acetabular components showed the evidence of osteolysis, vertical or horizontal migration.

\section{Complications}

$\mathrm{n}=34$

Table 7: Complications

\begin{tabular}{|c|c|c|}
\hline Complications & Frequency & Percentage \\
\hline Limb length discrepancy & 2 & 5.88 \\
\hline Superficial infection & 1 & 2.94 \\
\hline Sciatic nerve palsy & 1 & 2.94 \\
\hline Nil & 30 & 88.23 \\
\hline Total & 34 & 100 \\
\hline
\end{tabular}

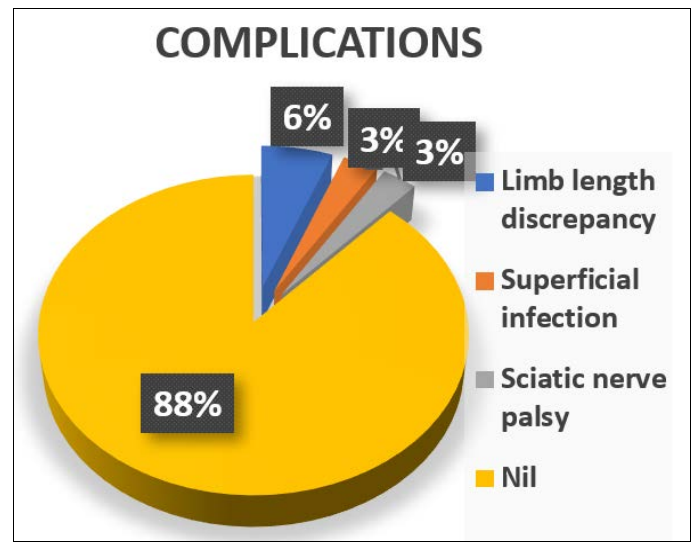

Fig 7: Complications 

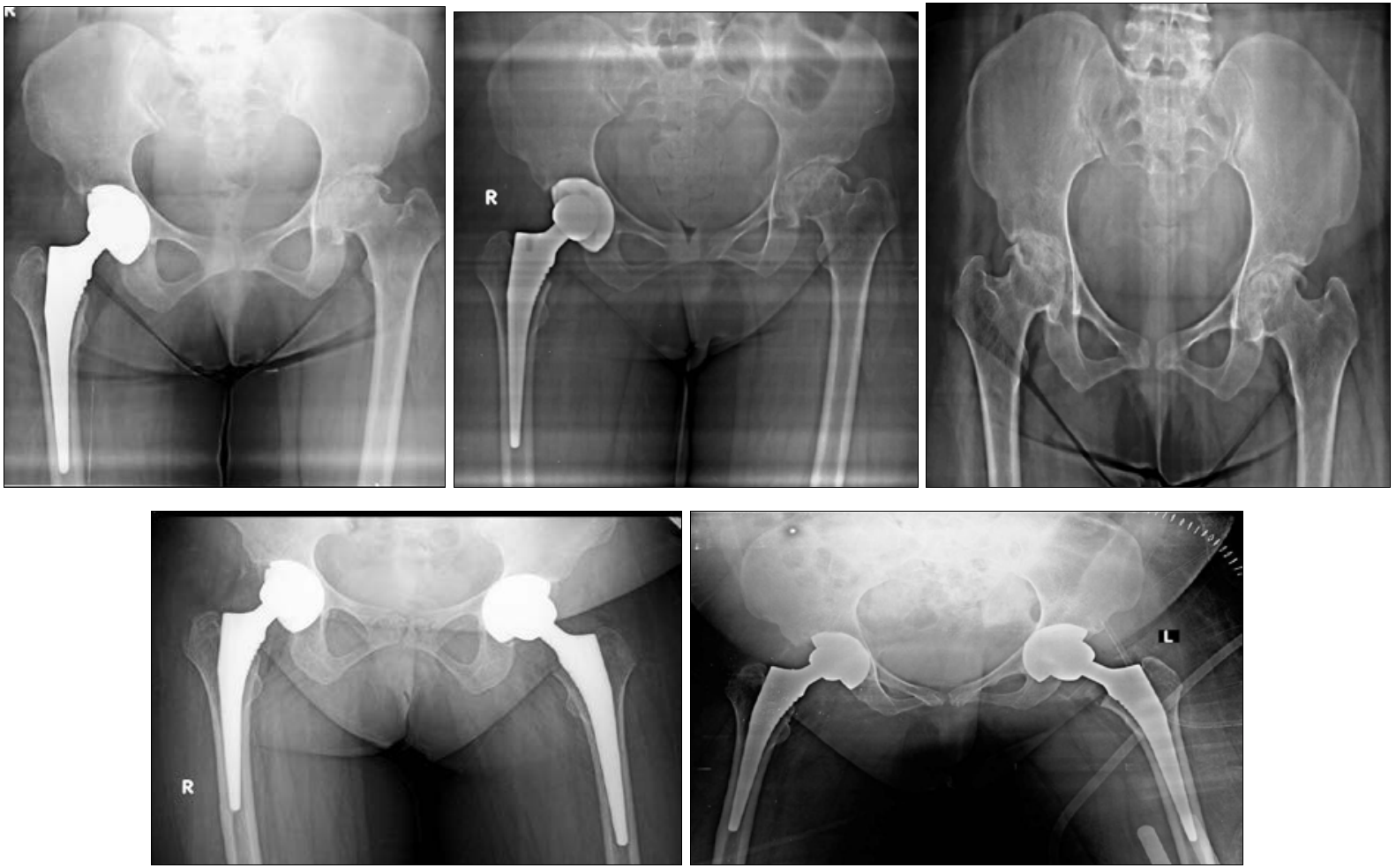

Fig 8: Image showing Bilateral AVN (Clockwise from Left Upper corner) preoperative X-Ray, postoperative on right side, follow up at 6 weeks, postoperative on left side, follow up at 24 weeks.

\section{Discussion}

- Total hip arthroplasty is a well-documented surgical procedure that relieves pain and

- functional disability experienced by patients with moderate to severe arthritis of hip, thus improving quality of life.

- $\quad$ Our study was carried out on 34 hips in 30 patients who underwent uncemented THR.

In our study, patients age group ranged from 21-68 years, out of which 5(16.67\%) were below 30 years, $6(20 \%)$ between 30-39 years, 12 (40\%) were between 40-49yrs, 2 (6.7\%) were between $50-59 y$ rs and $5(16.7 \%)$ were more than 60 years. The median age was $41.5 y e a r s$.

The main indication for surgery in our study was secondary OA in 30 hips (88\%) in which most commonly it was due to AVN (22 hips, 64.70\%) followed by trauma (3 hips, 8.82\%) rheumatoid arthritis (2 hips, 5.88\%) Ankylosing spondylitis (2 hips, 5.88\%) and DDH (1 hip,2.94\%). In the remaining 4 hips, it was due to primary OA $(12 \%)$ as compared to primary osteoarthritis as the most common indication in Western studies like McLaughlin ${ }^{[11]}$ et al 58\% and Berger ${ }^{[12]}$ et al $37 \%$. The above facts suggest the high rate of AVN and low rate of primary osteoarthritis in Indian patients.

All surgeries were performed in conventional operation theatre through posterior approach.

Uncemented press fit tapered stem-plasma coated was used in all patients. The stem size ranged from 8-14 and most commonly used was 10 (23.5\%).

The head used was made of cobalt chrome alloy, size ranged from 22-32 and most commonly used was 28(76.5\%). Press fit- plasma coated acetabular shell was used in all cases. The maximum shell size used was 58 and minimum was 38. Shell size 48 and 52 were the most commonly used (23.5\%). UHMWPE liner was used corresponding to the size of the head used. Size 28 was most frequently used (26hips, 76.5\%). The patients were followed up at regular intervals - 6weeks, 3 months and 6months. All patients were evaluated by the
Modified Harris hip score. In Our study we used new generation prosthesis which demonstrated improved clinical and radiological outcomes compared with early designs of prostheses inserted without cement.

Mean Harris hip score improved from 42.5 to 92.8 at last follow up, as compared to Kim ${ }^{[13]}$ et al study (from 48 to 92), McLaughlin ${ }^{[11]}$ et al (from 48 to 88), Katz ${ }^{[14]}$ et al (from 42 to 84) and Kawalkar ${ }^{[15]}$ et al (from 34 to 93) suggesting the marked improvement in the functional outcome after total hip arthroplasty.

A hip is graded as excellent for 90 to 100 points; good for 80 to 89 points; fair for 71-79 points; poor for 70 points and below. We had excellent results in 27 patients (90\%), good in 3 patients (10\%) as compared to Kim ${ }^{[13]}$ et al (43\% excellent, $52 \%$ good and $6 \%$ fair at the end of 2 years); Kawalkar ${ }^{[15]}$ et al (93\% Good to Excellent, 7\% Fair); McLaughlin ${ }^{[11]}$ et al (87\% Good to Excellent,7\% Fair and 6\% Poor).

The mean preoperative pain score was $12.33 \pm 4.30$ and it improved postoperatively to mean score of $42.20+1.99$ at last follow up indicating that Pain relief was dramatic following the total hip replacement. In a study by Joshi et $\mathrm{al}^{16}$, the pain score was excellent in $96 \%$ of hips, Berger et al ${ }^{\text {[12] }}$ (none or slight pain in $78 \%$ of hips) and Mclaughlin et al ${ }^{\text {[11] }}$ (92\% of hips with none or slight pain).

The mean preoperative functional score was $26.37 \pm 2.48$ and it improved postoperatively to mean score of $41.7 \overline{7} \pm 1.47$ at last follow up. In a study by Katz ${ }^{[14]}$ et al ambulation and functional ability improved in most of the patients. All patients didn't require support for walking at the end of our study as compared with Kim ${ }^{[13]}$ et al (88\% needed no support, $10 \%$ needed crutches), Mclaughlin et al ${ }^{[11]}$ (7\% always needed a cane for walking)

The mean preoperative absence of deformity score was $0.80 \pm$ 1.62 and it improved postoperatively to mean score of 4 at last 
follow up. The mean preoperative ROM score was $3.00 \pm$ 0.45 and it improved postoperatively to mean score of $4.83 \pm$ 0.37 at last follow up.

In our study $88 \%$ (30) of the cases had no complications. $12 \%$ (4cases) had complications which included limb length discrepancy (2 cases, 6\%), superficial infection (1 case, 3\%) and sciatic nerve palsy ( 1 case,3\%) which was comparable with Mclaughlin et al ${ }^{\text {[11] }}$ (2 cases of superficial infection and one case of partial sciatic nerve injury).

1 patient (3\%) had superficial infection, culture was negative and wound healed completely 2 weeks postoperatively. 1 patient (3\%) had sciatic nerve palsy which was managed with foot drop splint and recovered spontaneously by 3 months postoperatively. Postoperative LLD was not seen in 94\% of the study group. About 6\% (2 cases) of the study group had LLD of $1 \mathrm{~cm}$. The results were comparable with studies by Ranawat and Rodriguez et al ${ }^{[17]}$ (LLD of 1 to $1.8 \mathrm{~cm}$ ).

At last follow-up, no radiograph showed any evidence of new radiolucency or any shift in position of the femoral and acetabular components.

\section{Conclusion}

Chronic disabling conditions of the hip such as osteoarthritis, inflammatory arthritis and osteonecrosis has debilitated many patients. Secondary degenerative arthritis is more common than primary degenerative arthritis and has affected mainly the younger age group. Total hip arthroplasty is a welldocumented surgical procedure which has relieved the pain and functional disability experienced by patients with moderate to severe arthritis of the hip and aids in improving the quality of their life.

The outcome of total hip arthroplasty is determined by various factors like selection of patients, design of component and the operative technique. The results of the procedure needs long term studies to evaluate the complete effect.

Uncemented total hip arthroplasty is mainly indicated in young patients with high functional demand and adequate bone stock. We have evaluated Total hip arthroplasty, using uncemented prosthesis in a short duration follow up. Our study suggests that the current generation of uncemented prosthesis used in the total hip replacement for degenerative arthritis of hip, provides satisfactory clinical and radiological outcomes after a short duration of follow up. Even though the study was not free of complications, the overall functional and radiological outcome showed excellent results.

\section{References}

1. James W. Harkes, John R. Crockarell. Campbell's operative orthopaedics, chapter 3, Arthroplasty of hip; 13th edn.

2. Siopack JS, Jergesen HE. Total hip arthroplasty. West J Med 1995;162:243-249.

3. Carolina Santanna Umpierres, Tiango Aguiar Ribeiro, Angela Elisabete, Marchisio et al. Rehabilitation following total hip arthroplasty evaluation over short follow-up time: Randomized clinical trial. JRRD 2014; 51(10):1567-1578.

4. Arden N, Nevin MC. Osteoarthritis: epidemiology. Best Pract Res Clin Rheumatol 2006;20:3-25.

5. Felson DT. An update on the pathogenesis and epidemiology of osteoarthritis. Radiol Clin North Am 2004;42:1-9.

6. Zhang Y, Jordan JM. Epidemiology of osteoarthritis. Rheum Dis Clin North Am 2008;34:515-29.

7. Signe Rosenlund, Leif Broeng, Carsten Jensen, Anders
Holsgaard-Larsen et al. The effect of posterior and lateral approach on patient-reported outcome measures and physical function in patients with osteoarthritis, undergoing total hip replacement.

8. Petty WP, Saunders WB. Total Joint Replacement-VI, Lower Extremity Replacement. The Hip. Philadelphia, 1991;189-465.

9. McKee GK, WFJ. Replacement of arthritic hips by the McKee-Farrar prosthesis. J Bone Joint Surg [Br], 1966;48:245-259.

10. Faulkner A, Kennedy LG, Baxter K, Donovan J, Wilkinson M, Bevan G. Effectiveness of hip prostheses in primary total hip replacement: a critical review of evidence and an economic model, Health Technol Assess 1998;2:1-133.

11. Jeffrey R, McLaughlin Kyla, Lee R. Total hip arthroplasty with an uncemented femoral component' Bone Joint Surg (Br) 1997;79:9007.

12. Berger RA, Jacobs JJ, Quigely LR, Rosenberg AG. Galante jo Primary cementless acetabular reconstruction in patients younger than 50 years old. Clinical Orthopaedics and Related Research 1997;(344):216-226.

13. Kim YH1, Oh SH, Kim JS. Primary total hip arthroplasty with a second-generation cementless total hip prosthesis in patients younger than fifty years of age. J Bone Joint Surg Am 2003;85-A(1):109-14.

14. Katz RL, Boume RB, Rorabeck CH, Mc Gee H. Total hip arthroplasty in patients with avascular necrosis of hip. Follow up observations on cementless and cemented operations. Clin Orthop 1992;281:145-151.

15. Kawalkar AC, Badole CM, Phadke A. Midterm results of cementless total hip arthroplasty in young. J Orthop Allied Sci 2016;4:30-5.

16. Joshi AB, Markovic L, Hardinge K, Murphy JC. Total hip arthroplasty in Avascular necrosis: an analysis of 181 hips. J Arthroplasty 2002;17(4):427-33.

17. Chitranjan S Ranawat, Rodriguez. Functional leg length inequality following Total hip arthroplasty. The Journal of Arthroplasty 1997;(12)4:359-364. 